\title{
Highly Reliable White LEDs Using Nitride Phosphors
}

\author{
Rong-Jun Xie ${ }^{\dagger}$, Naoto Hirosaki, and Takashi Takeda \\ Sialon Group, Sialon Unit, Environment and Energy Materials Division, National Institute for Materials Science (NIMS), \\ Tsukuba, Japan
}

(Received May 22, 2012; Accepted June 12, 2012)

\begin{abstract}
Nitride phosphors are now attracting significant attention of material scientists and phosphor engineers, because they promise red-shifted photoluminescence spectra, small Stokes shift, high quantum efficiency and low thermal degradation. A number of interesting nitride phosphors have been developed and practiced for producing white light with LED chips. In this paper, the applications of nitride phosphors in highly reliable wLEDs will be overviewed.
\end{abstract}

Key words : Phosphor, Nitride, LED, Sialon, Photoluminescence

\section{Introduction}

$\mathrm{W}$ hite light-emitting diodes (wLEDs), known as the next-generation green and efficient solid state lighting technology, are now penetrating into our daily life steadily, replacing incandescent bulbs/fluorescent tubes for general lighting, cold cathode fluorescent lamps (CCFLs) for backlighting in liquid crystal displays (LCDs), as well as Xenon lamps for headlighting of vehicles. ${ }^{1)}$ Thanks to the advances in chip, phosphor and packaging technologies, the luminous efficacy of wLEDs is significantly enhanced. For example, Cree announced a top-level high-power wLED (CCT $=4408$ K) with the luminous efficacy as high as $254 \mathrm{~lm} / \mathrm{W}(350 \mathrm{~mA}$ forward current) recently. ${ }^{2)}$ As one of key materials in white LED technologies, phosphor plays a key role in the optical quality of wLEDs such as luminous efficiency, color temperature, color rendition, and the reliability (lifetime). ${ }^{1}$ Therefore, to achieve high performance white LEDs, the phosphor materials should be carefully selected and used.

In the wLED technologies, the emission of LED chips (blue or UV light) is down-converted into useful green, yellow, or red emission colors by phosphors. The phosphors are thus required to have (i) very strong absorption of the LED emissions; (ii) high conversion efficiency (quantum efficiency); (iii) small thermal quenching/degradation, and (iv) high stability against chemical attacks. ${ }^{1}$ Although a large amount of phosphors have been investigated in the literature, only a very small number of phosphors can be used practically. These phosphors include yttrium aluminum garnet $\left(\mathrm{Y}_{3} \mathrm{Al}_{5} \mathrm{O}_{12}: \mathrm{Ce}^{3+}\right),{ }^{3)}$ orthosilicates $\left(\mathrm{M}_{2} \mathrm{SiO}_{4}: \mathrm{Eu}^{2+}, \mathrm{M}=\mathrm{Ca}\right.$, $\mathrm{Sr}, \mathrm{Ba}){ }_{,}^{4)}$ alkaline earth metal sulfides (MS: $\mathrm{Eu}^{2+}, \mathrm{M}=\mathrm{Ca}$,

${ }^{\dagger}$ Corresponding author : Rong-Jun Xie

E-mail : Xie.Rong-Jun@nims.go.jp

Tel : +81-29-860-4312 Fax : +81-29-851-3613
$\mathrm{Sr})^{5)}$ and alkaline earth metal thiogallates $\left(\mathrm{MGa}_{2} \mathrm{~S}_{4}: \mathrm{Eu}, \mathrm{M}=\right.$ $\mathrm{Ca}, \mathrm{Sr}, \mathrm{Ba}) .^{6}$ But orthosilicate phosphors face the thermal quenching problem, and the sulfide-based phosphors are very moisture and thermal sensitive. Some modified YAG:Ce phosphors with redshifted emission colors also have the thermal stability problems, and their color points (chromaticity coordinates) change with increasing temperature. ${ }^{7)}$ These problems are making the phosphors not suitable for producing highly reliable white LEDs, and thermally-stable phosphors thus need to be developed.

Covalent nitride materials, including $\mathrm{Si}_{3} \mathrm{~N}_{4}$ and sialons, have long been investigated as structural ceramics due to their superior thermomechanical properties, high hardness, and chemical inertness. ${ }^{8}$ Doping nitrides with rare earth ions leads to a novel kind of luminescent materials which show redshifted photoluminescence spectra, abundant emission colors, high quantum efficiency and small thermal quenching. ${ }^{1.9)}$ The redshifted excitation and emission spectra are ascribed to strong crystal-field splitting and large nephelauxetic effect as the activator ions are covalently bonded to nitrogen at shorted distances. These interesting photoluminescence properties enable nitride phosphors to be very suitable for use in wLEDs.

A number of interesting nitride phosphors have been investigated, including blue-emitting JEM:Ce, ${ }^{10)} \mathrm{Y} / \mathrm{La}$-Si-O$\mathrm{N}: \mathrm{Ce},{ }^{1,12)} \mathrm{AlN}: \mathrm{Eu}^{13)}{ }^{13)} \mathrm{LaSi}_{3} \mathrm{~N}_{5}: \mathrm{Ce}^{14)}$ green-emitting $\beta$-sialon:Eu, ${ }^{15,16)}$ $\mathrm{SrSi}_{2} \mathrm{O}_{2} \mathrm{~N}_{2}: \mathrm{Eu},{ }^{17)} \mathrm{Ca}$ - $\alpha$-sialon: $: \mathrm{Yb}^{18)} \mathrm{Ba}_{3} \mathrm{Si}_{6} \mathrm{O}_{12} \mathrm{~N}_{2}: \mathrm{Eu}^{199}{ }^{19} \mathrm{Sr}_{5} \mathrm{Al}_{5+\mathrm{x}}$ $\mathrm{Si}_{21-\mathrm{x}} \mathrm{N}_{35-\mathrm{x}} \mathrm{O}_{2+\mathrm{x}}: \mathrm{Eu}^{20)} \mathrm{Sr}_{14} \mathrm{Si}_{68-\mathrm{s}} \mathrm{Al}_{6+\mathrm{s}} \mathrm{O}_{\mathrm{s}} \mathrm{N}_{106-\mathrm{s}}(\mathrm{s} \sim 7): \mathrm{Eu}^{21)} \mathrm{Sr}_{3} \mathrm{Si}_{13} \mathrm{Al}_{3}$ $\mathrm{O}_{2} \mathrm{~N}_{21}$ :Eu, ${ }^{22)} \quad$ g-alon:Mn, ${ }^{238}$ yellow-emitting Ca- $\alpha$-sialon:Eu, ${ }^{24,25}$ Li- $\alpha$-sialon: $\mathrm{Eu}^{26,27)} \mathrm{La}_{3} \mathrm{Si}_{6} \mathrm{~N}_{11}: \mathrm{Ce}^{28)} \mathrm{CaAlSiN}_{3}: \mathrm{Ce}^{29)}$ and red-emitting $\mathrm{CaAlSiN}_{3}: \mathrm{Eu}^{30)} \mathrm{M}_{2} \mathrm{Si}_{5} \mathrm{~N}_{8}: \mathrm{Eu}(\mathrm{M}=\mathrm{Ca}, \mathrm{Sr}, \mathrm{Ba}),{ }^{31)} \mathrm{CaSiN}_{2}: \mathrm{Eu} /$ $\mathrm{Ce},{ }^{32,33)}$ and $\mathrm{SrAlSi}_{4} \mathrm{~N}_{7}: \mathrm{Eu}^{34,35)}$ Using the nitride phosphors in wLEDs has also been attempted, leading to two types of wLEDs - one-phosphor-converted wLED (high efficiency) and multi-phosphor-converted wLEDs (high color rendition). ${ }^{1]}$ In this article, white LEDs prepared by using nitride 
phosphors will be overviewed.

\section{Nitride-phosphor-based white LEDs}

\subsection{One-phosphor-converted wLEDs}

The first commercialized white LED was produced by combining the yellow-emitting YAG:Ce with a blue LED chip. ${ }^{36)}$ This one-phosphor-converted or bichromatic white LED shows high luminous efficacy and the medium color rendering index $(\mathrm{Ra} \sim 70)$. Moreover, its color temperature is usually higher than $4500 \mathrm{~K}$ due to the deficiency of red component in the YAG:Ce emission spectrum. To achieve warm white light (i.e., low color temperature) the emission spectrum of YAG:Ce needs to be redshifted by partially substituting Gd for Y. ${ }^{7}$ However, the Gd-substituted YAG:Ce shows very larger thermal quenching compared to the unmodified YAG:Ce, as seen in Fig. 1. It means that the warm white is achieved by sacrificing the reliability of the wLED lamps.

The $\mathrm{Eu}^{2+}$-doped Ca- $\alpha$-sialon phosphor was reported to be a promising yellow luminescent material for white LEDs, which show a broad emission band centered at $\sim 585 \mathrm{~nm}^{24,25)}$ The orangish yellow emission color of Ca- $\alpha$-sialon:Eu makes warm white LEDs come true, as shown in Fig. 2. The correlated color temperature of the LED using Ca- $\alpha$-sialon:Eu is $2750 \mathrm{~K},{ }^{37)}$ compared to $5500 \mathrm{~K}$ of the LED using YAG:Ce (P46Y3). Furthermore, Ca- $\alpha$-sialon:Eu exhibits a smaller thermal quenching than YAG:Ce (See Fig. 1). Sakuma et $a l .{ }^{37)}$ reported that the color point shift of the wLED was 0.006 for Ca- $\alpha$-sialon:Eu, whereas it was 0.021 for YAG:Ce (P46Y3) when tested at $200^{\circ} \mathrm{C}$, indicative of the much higher reliability of the device by using nitride phosphors.

It has been addressed that the emission wavelength of $\alpha$ sialon:Eu can be tuned in a broad range by the composition tailoring. This enables $\alpha$-sialon:Eu phosphors to produce not only the warm white light but also the normal white light. For example, Li- $\alpha$-sialon:Eu has a shorted emission wavelength than Ca- $\alpha$-sialon: $\mathrm{Eu}$ when both the $\mathrm{m}(\mathrm{n})$ value and the Eu concentration are fixed. ${ }^{26)}$ Therefore, a white LED

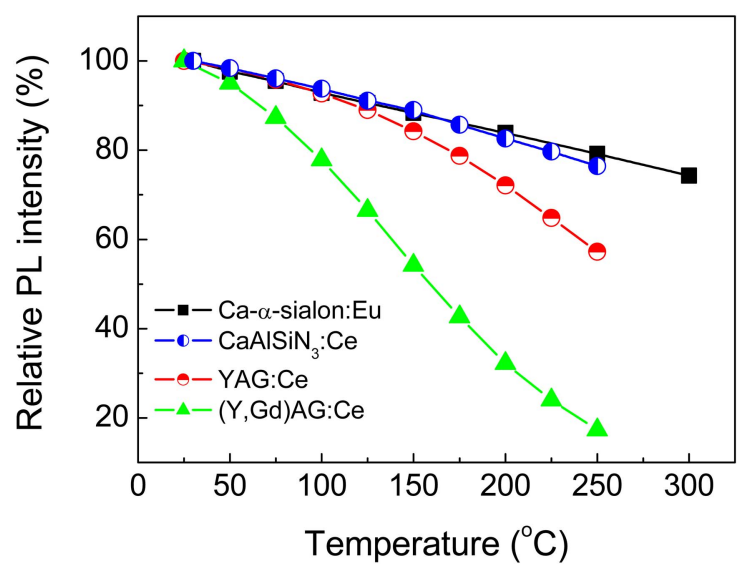

Fig. 1. Thermal quenching of Ca- $\alpha$-sialon:Eu, CaAlSiN ${ }_{3}: \mathrm{Ce}$ and YAG:Ce phosphors, measured upon the $450 \mathrm{~nm}$ excitation. with the correlated color temperature of $6150 \mathrm{~K}$ was realized by using the short-wavelength $\mathrm{Li}-\alpha$-sialon: $\mathrm{Eu}$.

Some other yellow nitride phosphors have also been reported, such as $\mathrm{La}_{3} \mathrm{Si}_{6} \mathrm{~N}_{11}: \mathrm{Ce}^{28)}$ and $\mathrm{CaAlSiN}_{3}: \mathrm{Ce}^{29)}$ The $\mathrm{CaAlSiN}_{3}$ :Ce phosphor shows a broad $\mathrm{Ce}^{3+}$ emission band centered at 570-603 $\mathrm{nm}$ and a large full-width at half maximum (FWHM) of $\sim 135 \mathrm{~nm}$. The combination of $\mathrm{CaAlSiN}_{3}: \mathrm{Ce}$ with a blue LED chip leads to the white light with the correlated color temperature of $3722 \mathrm{~K}$. Moreover, $\mathrm{CaAlSiN}_{3}: \mathrm{Ce}$ has a small thermal quenching (See Fig. 1). Similar to $\mathrm{CaAlSiN}_{3}$ : $\mathrm{Ce}, \mathrm{La}_{3} \mathrm{Si}_{6} \mathrm{~N}_{11}$ :Ce also shows an emission band with two sub-peaks at 543 and $585 \mathrm{~nm}$, and a good thermal stability. Suehiro et $a l^{38)}$ reported that the wLED using $\mathrm{La}_{3} \mathrm{Si}_{6} \mathrm{~N}_{11}$ : Ce had the color temperature of $2900-3700 \mathrm{~K}$.

Although nitride yellow phosphors have higher thermal stability than YAG:Ce, the quantum efficiency of YAG:Ce is the highest. For example, the external quantum efficiency of YAG:Ce is as high as $80 \%$, but it is about $60 \%, 56 \%$ and $42 \%$ for $\alpha$-sialon:Eu, $\mathrm{CaAlSiN}_{3}$ :Ce and $\mathrm{La}_{3} \mathrm{Si}_{6} \mathrm{~N}_{11}$ :Ce respectively. Therefore, YAG:Ce is still the most popular yellow phosphor used in wLEDs, typically in high color temperature wLEDs. On the other hand, nitride yellow phosphors have advantages in producing highly reliable wLEDs with low color temperatures.

\subsection{Multi-phosphor-converted wLEDs}

The one-phosphor-converted wLEDs usually have high luminous efficacy because to some degree their emission spectra resemble the human eye sensitive curve which has the maximum at $555 \mathrm{~nm}$. However, the color rendition of the one-phosphor-converted wLEDs is in the range of $\mathrm{Ra}=$ 60-75, which is not acceptable for general lighting. To improve the color rendering properties of wLEDs, green and red phosphors instead of a single yellow phosphor are required to combine with LED chips to produce an emission spectrum covering the most part of the visible spectral region.

The green phosphors investigated earlier are alkaline earth orthosilicates $\left(\mathrm{M}_{2} \mathrm{SiO}_{4}: \mathrm{Eu}, \mathrm{M}=\mathrm{Ca}, \mathrm{Sr}, \mathrm{Ba}\right)$ and thiogallates $\left(\mathrm{MGa}_{2} \mathrm{~S}_{4}: \mathrm{Eu}, \mathrm{M}=\mathrm{Ca}, \mathrm{Sr}, \mathrm{Ba}\right)$. But both of these

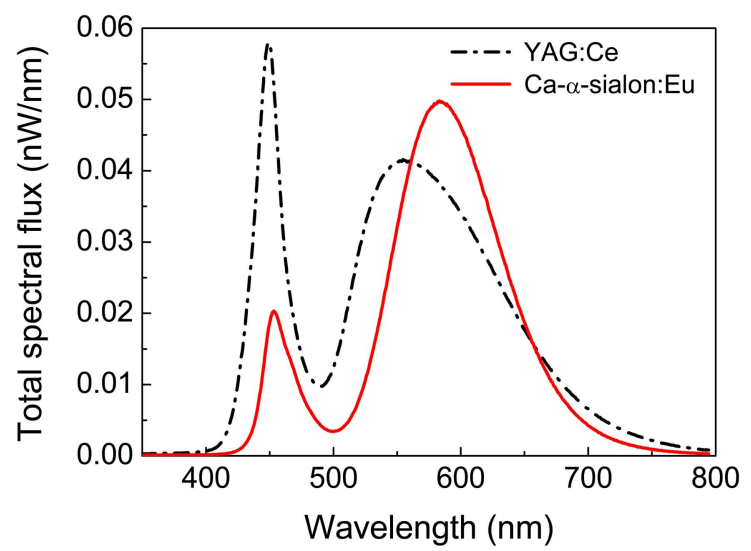

Fig. 2. Emission spectra of wLEDs using YAG:Ce and Ca- $\alpha-$ sialon: $\mathrm{Eu}$ 


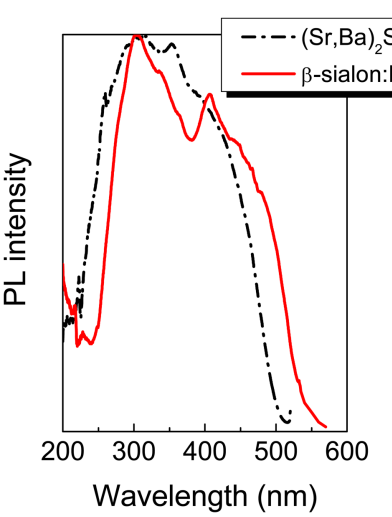

(a)

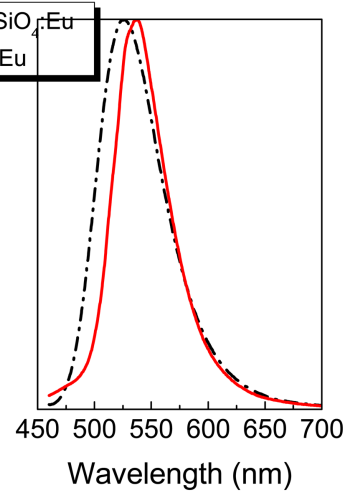

(b)
Fig. 3. Excitation (a) and emission (b) spectra of green-emitting $(\mathrm{Sr}, \mathrm{Ba})_{2} \mathrm{SiO}_{4}: \mathrm{Eu}$ and $\beta$-sialon:Eu.

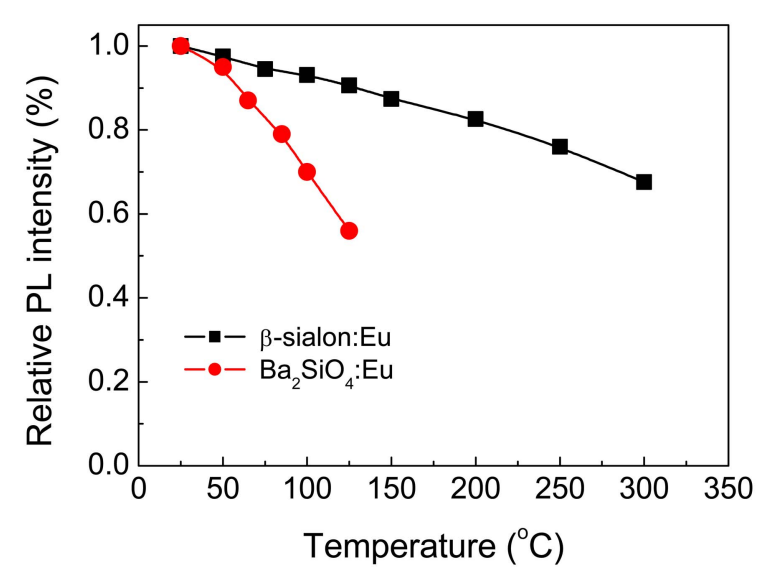

Fig. 4 .Thermal quenching of $\mathrm{Ba}_{2} \mathrm{SiO}_{4}: \mathrm{Eu}$ and $\beta$-sialon:Eu.

phosphors have the problems of large thermal quenching and moisture sensitivity. It is also true for the red-emitting alkaline earth metal sulfides (MS:Eu, $\mathrm{M}=\mathrm{Ca}, \mathrm{Sr}$ ). To find more reliable green and red phosphors are thus very urgent and important. Thanks to the large crystal-field splitting and nephelauxetic effect in covalent nitride host crystals, some interesting green and red nitride phosphors have been discovered recently.

The first green nitride phosphor is $\mathrm{Eu}^{2+}$-doped $\beta$-sialon. Fig. 3 is shown the photoluminescence spectra of $\beta$-sialon:Eu and $(\mathrm{Sr}, \mathrm{Ba})_{2} \mathrm{SiO}_{4}: \mathrm{Eu}$. Compared to the $(\mathrm{Sr}, \mathrm{Ba})_{2} \mathrm{SiO}_{4}: \mathrm{Eu}$ green phosphor, $\beta$-sialon:Eu shows a much more redshifted excitation spectrum and a narrower emission band. Furthermore, $\beta$-sialon:Eu has the much smaller thermal quenching than the orthosilicate counterpart(Fig. 4).

Turning to the red phosphors, $\mathrm{M}_{2} \mathrm{Si}_{5} \mathrm{~N}_{8}$ : Eu and CaAlSiN $\mathrm{C}_{3}: \mathrm{Eu}$ are very efficient red-emitting nitride phosphors that have quantum efficiencies (internal) higher than 90\%. ${ }^{1,39)}$ Both phosphors show the similar photoluminescence spectra (See in Fig. 5), but $\mathrm{CaAlSiN}_{3}$ :Eu has better thermal stability than $\mathrm{Sr}_{2} \mathrm{Si}_{5} \mathrm{~N}_{8}:$ Eu.

High color rendering wLEDs are achieved by combining blue/UV LED chips with green/red phosphors (two-phosphor-converted), green/yellow/red phosphors (three-phos-

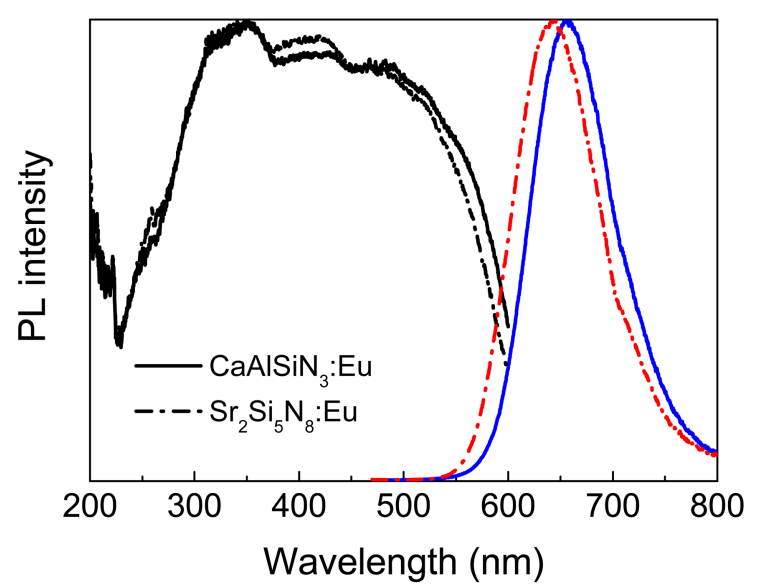

Fig. 5. Photoluminescence spectra of $\mathrm{Sr}_{2} \mathrm{Si}_{5} \mathrm{~N}_{8}: \mathrm{Eu}$ and $\mathrm{CaAlSiN}_{3}: \mathrm{Eu}$.

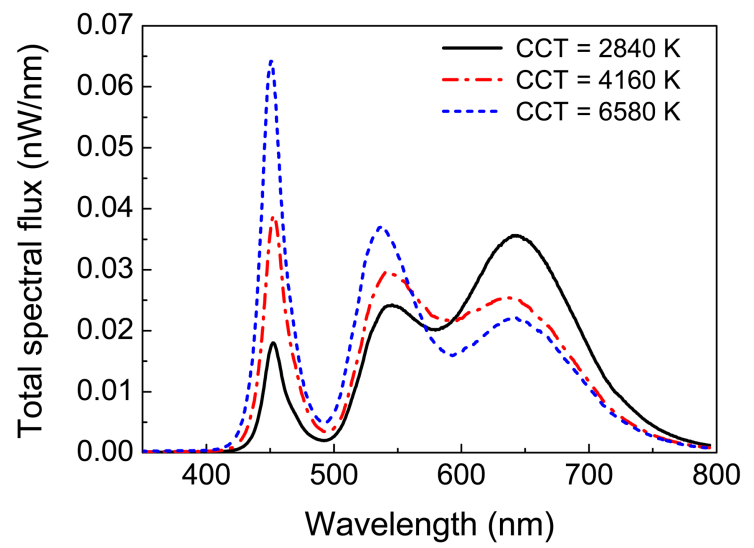

Fig. 6. Emission spectra of high color rendering wLEDs using $\beta$-sialon:Eu, $\alpha$-sialon:Eu and $\mathrm{CaAlSiN}_{3}$ :Eu.

phor-converted), or blue/green/yellow/red phosphors (fourphosphor-converted). ${ }^{1)}$ Table 1 lists the wLEDs examples prepared by nitride phosphors. It is seen that the color rendering index is significantly enhanced by using the phosphor blend, and the luminous efficacy is still much higher than that of incandescent lamps $(15 \mathrm{~lm} / \mathrm{W})$. Fig. 6 is shown the three-phosphor-converted wLEDs using $\beta$-sialon:Eu, $\mathrm{Ca}-\alpha$-sialon:Eu and $\mathrm{CaAlSiN}_{3}: \mathrm{Eu}$. The color temperature is tunable by simply adjusting the phosphor blending ratio. The color rendering index is in the range of $81-88,{ }^{44)}$ which is suitable for home illumination. Furthermore, the R9 color rendering index, reflecting the red color, is as high as 96, which is usually a minus value for the one-phosphor-converted wLEDs. For achieving higher color rendition, four phosphors are applied in wLEDs, leading to super-high color rendering index of 95 (See Table 1). ${ }^{45)}$

\section{Summary and Outlook}

There are numerous phosphors that have been investigated for use in white LEDs, but only a very few number of them are technologically important. The quantum efficiency and reliability (thermal/chemical stability) are two of key 
Table 1. High Color Rendering White LEDs using Nitride Phosphors

\begin{tabular}{|c|c|c|c|}
\hline Phosphors & $\mathrm{Ra}$ & $\eta(\operatorname{lm} / \mathrm{W})$ & Ref. \\
\hline $\mathrm{SrSi}_{2} \mathrm{O}_{2} \mathrm{~N}_{2}: \mathrm{Eu}+\mathrm{Sr}_{2} \mathrm{Si}_{5} \mathrm{~N}_{8}: \mathrm{Eu}$ & $89-91$ & $25^{*}$ & 40 \\
\hline $\mathrm{SrSi}_{2} \mathrm{O}_{2} \mathrm{~N}_{2}: \mathrm{Eu}+\mathrm{CaSiN}_{2}: \mathrm{Eu}$ & 90.5 & 30 & 41 \\
\hline$\alpha$-sialon: $\mathrm{Yb}+\mathrm{Sr}_{2} \mathrm{Si}_{5} \mathrm{~N}_{8}: \mathrm{Eu}$ & $82-83$ & $17-23$ & 42 \\
\hline$(\mathrm{Ca}, \mathrm{Sr})_{2} \mathrm{SiO}_{4}: \mathrm{Eu}+\mathrm{Sr}_{3} \mathrm{Si}_{13} \mathrm{Al}_{3} \mathrm{O}_{2} \mathrm{~N}_{21}: \mathrm{Eu}$ & $82-88$ & $56-62$ & 22 \\
\hline$\beta$-sialon: $\mathrm{Eu}+\mathrm{CaAlSiN}_{3}: \mathrm{Eu}$ & & 38 & 43 \\
\hline$\beta$-sialon: $\mathrm{Eu}+\alpha$-sialon: $\mathrm{Eu}+\mathrm{CaAlSiN}_{3}: \mathrm{Eu}$ & $81-88$ & $24-28$ & 44 \\
\hline $\mathrm{BaSi}_{2} \mathrm{O}_{2} \mathrm{~N}_{2}: \mathrm{Eu}+\beta$-sialon:Eu $+\alpha$-sialon:Eu $+\mathrm{CaAlSiN}_{3}: \mathrm{Eu}$ & $95-96$ & $28-35$ & 45 \\
\hline JEM:Ce $+\beta$-sialon: $\mathrm{Eu}+\alpha$-sialon: $\mathrm{Eu}+\mathrm{CaAlSiN}_{3}: \mathrm{Eu}$ & $95-96$ & $19-20$ & 10 \\
\hline
\end{tabular}

$*$ Measured at $1 \mathrm{~A}$ forward current.

factors determining the value of phosphors. Due to their unique crystal structure and covalent chemical bonding, nitride phosphors show high quantum efficiency, significantly redshifted photoluminescence spectra, very small thermal quenching and high chemical stability, demonstrating their superior suitability in preparing highly reliable wLEDs. The experimental results clearly indicate that nitride phosphors have obvious advantages in producing warm white LEDs as well as high color rendition wLEDs.

In fact, not all nitride phosphors exhibit excellent thermal properties and reliability. With no doubts, this will push us to develop novel phosphor materials, and clarify the thermal quenching/degradation mechanisms and find solutions for those nitride phosphors with good photoluminescence properties but with bad thermal properties. At the same time, much attention should be paid to use the phosphor(s) correctly (in combination with the epoxy resin and the packing configuration), to obtain wLEDs with higher efficiency and reliability.

\section{REFERENCES}

1. R. -J. Xie, Y. Q. Li, N. Hirosaki, and H. Yamamoto, Nitride phosphors and Solid State Lighting, CRC Press (Taylor \& Francis Group), Boca Raton, 2011.

2. http://www.cree.com/news-and-events/cree-news/pressreleases/ 2012/april/120412-254-lumen-per-watt

3. G. Blasse, and A. Brill, "A New Phosphor for Flying-spot Cathode-ray Tubes for Colour Television: Yellow-emitting $\mathrm{Y}_{3} \mathrm{Al}_{5} \mathrm{O}_{12}: \mathrm{Ce}^{3+}$," Appl. Phys. Lett., 11 [2] 53-55 (1967).

4. J. K. Park, C. H. Kim, S. H. Park, H. D. Park, and S. Y Chois, "Application of Strontium Silicate Yellow Phosphor for White Light-emitting Diodes," Appl. Phys. Lett. 84 1647-49 (2004).

5. D. Poelman, J. E. Haecke, and P. F. Smet, "Advances in Sulfide Phosphors for Displays and Lighting," J. Mater. Sci: Mater Electron, 20 S134-S138 (2009).

6. Y. R. Do, K. Y. Ko, S. H. Na, and Y.D. Huh, "Luminescence Properties of Potential $\mathrm{Sr}_{1-\mathrm{x}} \mathrm{Ca}_{\mathrm{x}} \mathrm{Ga}_{2} \mathrm{~S}_{4}$ :Eu Green and Greenish-yellow-emitting Phosphors for White LED," J. Electrochem. Soc., 153 H142-H146 (2006).

7. V. Banchmann, C. Ronda, and A. Meijerink, "Temperature Quenching of Yellow $\mathrm{Ce}^{3+}$ Luminescence in YAG:Ce,"
Chem. Mater., 21 2077-84 (2009).

8. G. Z. Cao, and R. Metselaar, " $\alpha$ '-Sialon Ceramics, A Review," Chem. Mater., 3 242-52 (1991).

9. R. -J. Xie and N. Hirosaki, "Silicon-based Oxynitride and Nitride Phosphors for White LEDs-A Review," Sci. Tech. Adv. Mater., 8 588-600 (2007).

10. K. Takahashi, N. Hirosaki, R. -J. Xie, M. Harada, K. Yoshimura, and Y. Tomomura, "Luminescence Properties of Blue $\mathrm{La}_{1-\mathrm{x}} \mathrm{Ce}_{\mathrm{x}} \mathrm{Al}\left(\mathrm{Si}_{6-\mathrm{z}} \mathrm{Al}_{z}\right)\left(\mathrm{N}_{10-\mathrm{z}} \mathrm{O}_{\mathrm{z}}\right)(\mathrm{z} \sim 1)$ Oxynitrides Phosphors and Their Application in White Light-emitting Diode," Appl. Phys. Lett., 91091923 (2007).

11. J. W. H. van Krevel, H. T. Hintzen, R. Metselaar, and A. Meijerink, "Long Wavelength $\mathrm{Ce}^{3+}$ Emission in Y-Si-O-N Materials," J. Alloys Compd., 268 272-77 (1998).

12. B. Dierre, R. -J. Xie, N. Hirosaki, and T. Sekiguchi, "Blue Emission of $\mathrm{Ce}^{3+}$ in Lanthanide Silicon Oxynitride Phosphors," J. Mater. Res., 22 1933-41 (2007).

13. K. Inoue, N. Hirosaki, R. -J. Xie, and T. Takeda, "Highly Efficient and Thermally Stable Blue-emitting AlN:Eu ${ }^{2+}$ Phosphor for Ultraviolet White Light-emitting Diodes," $J$. Phys. Chem., C 133 9392-97 (2009).

14. T. Suehiro, N. Hirosaki, R. -J. Xie, and T. Sato, "Blue-emitting $\mathrm{LaSi}_{3} \mathrm{~N}_{5}: \mathrm{Ce}^{3+}$ Fine Powder Phosphor for UV-converting White Light Diodes," Appl. Phys. Lett., 95051903 (2009).

15. N. Hirosaki, R. -J. Xie, K. Kimoto, T. Sekiguchi, Y. Yamamoto, T. Suehiro, and M. Mitomo, "Characterization and Properties of Green-Emitting $\beta$-SiAlON:Eu ${ }^{2+}$ Powder Phosphors for White Light-Emitting Diodes," Appl. Phys. Lett., 86 211905-1-211905-3 (2005).

16. R.-J. Xie, N. Hirosaki, H. L. Li, Y. Q. Li, and M. Mitomo, "Synthesis and Photoluminescence Properties of $\beta$-sialon: $\mathrm{Eu}^{2+}$ $\left(\mathrm{Si}_{6-\mathrm{z}} \mathrm{Al}_{\mathrm{z}} \mathrm{O}_{\mathrm{z}} \mathrm{N}_{8-\mathrm{z}}: \mathrm{Eu}^{2+}\right)$-A Promising Green Oxynitride Phosphor For white Light-emitting Diodes," J. Electrochem. Soc., 154 J314-J319 (2007).

17. V. Bachmann, C. Ronda, O. Oeckler, W. Schnick, and M. Meijerink, "Color Point Tuning for (Sr,Ca,Ba)SiON:Eu for White Light LEDs," Chem. Mater., 21 316-25 (2009).

18. R. -J. Xie, N. Hirosaki, M. Mitomo, K. Uheda, T. Suehiro, X. Xu, Y. Yamamoto, and T. Sekiguchi, "Strong Green Emission from $\alpha$-sialon Activated by Divalent Ytterbium Under Blue Light Irradiation,” J. Phys. Chem., B109 94909494 (2005)

19. K. Uheda, S. Shimooka, M. Mikami, H. Imura, and N. Kijima, "Synthesis and Characterization of New Green Oxonitridosilicate Phosphor, $(\mathrm{Ba}, \mathrm{Eu})_{3} \mathrm{Si}_{6} \mathrm{O}_{12} \mathrm{~N}_{2}$, for White 
LED," Paper Presented at the for $214^{\text {th }}$ ECS Meeting, Hawaii, 2008.

20. O. Oeckler, J. A. Kechele, H. Koss, P. J. Schmidt, and W. Schnick, " $\mathrm{Sr}_{5} \mathrm{Al}_{5+\mathrm{x}} \mathrm{Si}_{21-\mathrm{x}} \mathrm{N}_{35-\mathrm{x}} \mathrm{O}_{2+\mathrm{x}}: \mathrm{Eu}^{2+}(\mathrm{x} \approx 0)$-A Novel Green Phosphor for White Light pcLEDs with Disordered Intergrowth Structure," Chem. Eur. J., 15 5311-19 (2009).

21. K. Shioi, Y. Michiue, N. Hirosaki, R. -J. Xie, T. Takeda, Y. Matsushita, M. Tanaka, and Y.Q. Li, "Synthesis and Photoluminescence of a Novel Sr-SiAlON: $\mathrm{Eu}^{2+}$ Blue-green Phosphor $\mathrm{Sr}_{14} \mathrm{Si}_{68-\mathrm{s}} \mathrm{Al}_{6+\mathrm{s}} \mathrm{O}_{\mathrm{s}} \mathrm{N}_{106-\mathrm{s}}(\mathrm{s} \sim 7)$," J. Alloy Compds., 509 [2] 332-37 (2011).

22. Y. Fukuda, K. Ishida, I. Mitsuishi, and S. Nunoue, "Luminescence Properties of $\mathrm{Eu}^{2+}$-doped Green-emitting Sr-sialon Phosphor and Its Application to White Light-emitting Diodes," Appl. Phys. Express, 2012401 (2009).

23. R. -J. Xie, N. Hirosaki, X. J. Liu, T. Takeda, and H. L. Li, "Crystal Structure and Photoluminescence of $\mathrm{Mn}^{2+}-\mathrm{Mg}^{2+}$ Codoped Gamma Aluminum Oxynitride ( $\gamma$-alon): A Promising Green Phosphor for White Light-emitting Diodes," Appl. Phys. Lett., 92201905 (2008).

24. R. -J. Xie, N. Hirosaki, K. Sakuma, Y. Yamamoto, and M. Mitomo, " $\mathrm{Eu}^{2+}$-doped Ca-alpha-SiAlON: A Yellow Phosphor for White Light-Emitting Diodes," Appl. Phys. Lett., 84 5404-06 (2004).

25. R. -J. Xie, N. Hirosaki, M. Mitomo, Y. Yamamoto, and T. Suehiro, "Optical Properties of $\mathrm{Eu}^{2+}$ in $\alpha$-SiAlON," J. Phys. Chem. B, 108 12027-31 (2004).

26. R. -J. Xie, N. Hirosaki, M. Mitomo, K. Sakuma, and N. Kimura, "Wavelength-tunable and Thermally Stable Li- $\alpha$ sialon: $\mathrm{Eu}^{2+}$ Oxynitride Phosphors for White Light-emitting Diodes," Appl. Phys. Lett., 89241103 (2006).

27. R. -J. Xie, N. Hirosaki, M. Mitomo, K. Takahashi, and K. Sakuma, "Highly Efficient White-light-emitting Diodes Fabricated with Short-wavelength Yellow Oxynitride Phosphors," Appl. Phys. Lett., 88101104 (2006).

28. T. Seto, N. Kijima, and N. Hirosaki, "A New Yellow Phosphor $\mathrm{La}_{3} \mathrm{Si}_{6} \mathrm{~N}_{11}: \mathrm{Ce}^{3+}$ for White LEDs," ECS Trans., 25 247$52(2009)$

29. Y. Q. Li, N. Hirosaki, R. -J. Xie, T. Takeda, and M. Mitomo, "Yellow-orange-emitting $\mathrm{CaAlSiN}_{3}: \mathrm{Ce}^{3+}$ Phosphor: Structure, Photoluminescence, and Application in White LEDs," Chem. Mater., 20 6704-14 (2008).

30. K. Uheda, N. Hirosaki, Y. Yamamoto, A. Naoto, T. Nakajima, and H. Yamamoto, "Luminescence Properties of A Red Phosphor, CaAlSiN $3: \mathrm{Eu}^{2+}$, for White Light-emitting Diodes," Electrochem. Solid State Lett., 9 H22-H25 (2006).

31. Y.Q. Li, J.E.J. van Steen, J.W.H. van Krevel, G. Botty, A.C.A. Delsing, F.J. DiSalvo, G. de With, and H.T. Hintezen, "Luminescence Properties of Red-emitting $\mathrm{M}_{2} \mathrm{Si}_{5} \mathrm{~N}_{8}: \mathrm{Eu}^{2+}(\mathrm{M}=\mathrm{Ca}$, Sr, Ba) LED Conversion Phosphors," J. Solid State Compd., 417 273-79 (2006).

32. R. Le Toquin and A.K. Cheetham, "Red-emitting Ceriumbased Phosphor Materials for Solid State Lighting Applications," Chem. Phys. Lett., 423 352-56 (2006).
33. C. J. Duan, X. J. Wang, W. M. Otten, A. C.A. Delsing, J.T. Zhao, and H.T. Hintzen, "Preparation, Electronic Structure, and Photoluminescence Properties of $\mathrm{Eu}^{2+}$ - and $\mathrm{Ce}^{3+} /$ $\mathrm{Li}^{+}$-activated Alkaline Earth Silicon Nitride $\mathrm{MSiN}_{2}(\mathrm{M}=\mathrm{Sr}$, Ba)," Chem. Mater., 20 1597-605 (2008).

34. C. Hecht, F. Stadler, P. J. Schmidt, S.J . auf der Gunne, V. Baumann, and W. Schnick, " $\mathrm{SrAlSi}_{4} \mathrm{~N}_{7}: \mathrm{Eu}^{2+}$-A Nitridoalumosilicate Phosphor for Warm White-Light (pc)LEDs with EdgeSharing Tetrahedra," Chem. Mater., 21 1595-601 (2009).

35. J. Ruan, R. -J. Xie, N. Hirosaki, and T. Takeda, "Nitrogen Gas Pressure Synthesis and Photoluminescent Properties of Orange-Red $\mathrm{SrAlSi}_{4} \mathrm{~N}_{7}: \mathrm{Eu}^{2+}$ Phosphors for White LightEmitting Diodes," J. Am. Ceram. Soc., 94 [2] 536-42 (2011).

36. S. Nakamura, and G. Fasol. The blue laser diode. New York: Spinger, 1997.

37. K. Sakuma, K. Omichi, N. Kimura, M. Ohashi, D. Tanaka, N. Hirosaki, Y. Yamamoto, R.-J. Xie, and T. Suehiro, "Warm-white Light-emitting Diode with Yellowish Orange SiAlON Ceramic Phosphor," Opt. Lett., 29 2001-3 (2004).

38. T. Suehiro, N. Hirosaki, and R. -J. Xie, "Synthesis and Photoluminescent Properties of $(\mathrm{La}, \mathrm{Ca})_{3} \mathrm{Si}_{6} \mathrm{~N}_{11}: \mathrm{Ce}^{3+}$ Fine Powder Phosphors for Solid-State Lighting," ACS Appl. Mater. Interfaces, 3 [3] 811-16 (2011).

39. R.-J. Xie, N. Hirosaki, T. Suehiro, F. -F. Xu, and M. Mitomo, "A simple, Efficient Synthetic Route to $\mathrm{Sr}_{2} \mathrm{Si}_{5} \mathrm{~N}_{8}: \mathrm{Eu}^{2+}$. based Red Phosphors for White Lighting-emitting Diodes," Chem. Mater., 18 5578-83 (2006).

40. R. Mueller-Mach, G. Mueller, M.R. Krames, H.A. Hoppe, F. Stadler, W. Schnick, T. Juestel, and P. Schmidt, "Highly Efficient All-nitride Phosphor-converted white Light Emitting Diode," Phy. Stat. Sol., (a) 202 1727-32 (2005).

41. C.C. Yang, C.M. Lin, Y.J. Chen, Y.T. Wu, S.R. Chuang, R.S. Liu, and S.F. Hu, "Highly Stable Three-band White Light from an InGaN-based Blue Light-emitting Diode Chip Precoated Wit (oxy) Nitride Green/red Phosphors," Appl. Phys. Lett., 90123503 (2007).

42. R .-J. Xie, N. Hirosaki, N. Kimura, K. Sakuma, and M. Mitomo, "2-phosphor-converted White Light-emitting Diodes Using Oxynitride/nitride Phosphors," Appl. Phys. Lett., 90 191101 (2007).

43. R. -J. Xie, N. Hirosaki, and T. Takeda, "Wide Color Gamut Backlight for Liquid Crystal Displays using Three-band Phosphor-converted white Light-emitting Diodes," Appl. Phys. Express, 2022401 (2009).

44. K. Sakuma, N. Hirosaki, N. Kimura, M. Ohashi, R. -J. Xie, Y. Yamamoto, T. Suehiro, K. Asano, and D. Tanaka, "White Light-emitting Diode Lamps using Oxynitride and Nitride Phosphor Materials," IEICE Trans. Electron., E88-C 2057 64 (2005).

45. N. Kimura, K. Sakuma, S. Hirafune, K. Asano, N. Hirosaki, R.-J. Xie, "Extrahigh Color Rendering White Lightemitting Diode Lamps using Oxynitride and Nitride Phosphors Excited by Blue Light-emitting Diode," Appl. Phys. Lett., 90051109 (2007). 